\title{
Visões e reflexões sobre as representações do tempo
}

\author{
Patricio DUGNANI ${ }^{1}$
}

\begin{abstract}
Resumo:
Este artigo pretende analisar e comparar a representação do tempo em diferentes épocas, para refletir sobre a relação entre a percepção do tempo e a existência humana. Observar que o ser humano, em diferentes períodos, percebe e representa o tempo de maneiras diferentes. A partir de levantamento bibliográfico, buscar, de maneira exploratória, selecionar algumas representações de diferentes períodos - Idade Média, Barroco, Modernidade e Pós-Modernidade - para compreender como o ser humano procurou representar, por meio de imagens e textos, os fenômenos temporais.
\end{abstract}

Palavras-chave: Representação. Imaginário. Percepção.

\section{Views and reflections on time representations}

\begin{abstract}
:
This article intends to analyze and compare the representation of time in different times, to reflect on the relationship between the perception of time and human existence. It is observed that the human being, in different periods perceives and represents the time in different ways, and thus, from a bibliographical survey, it was searched in an exploratory way, to select some representations of different periods - Middle Age, Baroque, Modernity and Postmodernity - to understand how the human being sought to represent, through images and texts, the temporal phenomena.
\end{abstract}

Keywords: Representation. Imaginary. Perception.

\section{Vistas y reflexiones sobre representaciones temporales}

\section{Resumen:}

Este artículo tiene como objetivo analizar y comparar la representación del tiempo en diferentes momentos para reflexionar sobre la relación entre la percepción del tiempo y la existencia humana. Observe que el ser humano, en diferentes períodos, percibe y representa el tiempo de diferentes maneras. A partir de una encuesta bibliográfica, busque, de manera exploratoria, seleccione algunas representaciones de diferentes períodos (Edad Media, Barroco, Modernidad y Postmodernidad) para comprender cómo el ser humano buscó representar, a través de imágenes y textos, fenómenos temporales.

Palabras clave: Tiempo. Representación. Imaginario. Percepción.

\section{Introdução}

Santo Agostinho buscando conceituar o tempo, um fenômeno que tem perturbado a existência humana desde seus primórdios, afirmou: "Se ninguém me pergunta, eu o sei;

\footnotetext{
${ }^{1}$ Doutor em Comunicação e Semiótica. Professor da Universidade Presbiteriana Mackenzie. patricio@mackenzie.br.
} 
mas se me perguntam, e quero explicar, não sei mais nada" (AGOSTINHO, 2007, XI, 14, 17).

Mediante a essa falta de possibilidade para determinar o que é o tempo, pode-se buscar explicações na física, como sendo uma dimensão. Na verdade, a quarta dimensão, depois de altura, largura, ou volume.

Pode-se pensar, também, no tempo, e buscar conceituá-lo, de maneira fenomenológica, como nossa percepção da passagem dos acontecimentos, ou sua duração. Ou é possível pensar o tempo de maneira kantiana, como um a priori fundamental do pensamento humano. Pode-se pensar no tempo como sendo as horas, os dias, a passagem do sol e a chegada da noite. Enfim, o tempo é um desses fenômenos físicos da natureza, uma percepção, uma interpretação do mundo, ou quiçá, uma representação simbólica do pensamento. O tempo pode ser pensado e sentido de diferentes maneiras (AGOSTINHO, 2007; FIORIN, 1996).

Mas, afinal, o que é o tempo? Nesse sentido, para este artigo, concorda-se com a afirmação do filósofo medieval. Como Santo Agostinho, e talvez de maneira mais obtusa, penso saber o que é o tempo, embora não saiba explicá-lo. Sequer consigo expressá-lo, adequadamente, de maneira mais objetiva, por meio dos conceitos científicos.

Porém, essa incerteza sobre o que é o tempo acaba por fazer com que, de maneira fértil, as civilizações procurem representá-lo das maneiras mais variadas. Cada período parece inventar sua representação do tempo. Dessa forma, acredito que os seres humanos, durante a sua existência, também ficaram em dúvida em como explicar o fenômeno tempo. O tempo é perturbador, o tempo apresenta-se como um enigma para a humanidade. O tempo nos assusta desde os primórdios das civilizações. Digo isso, pois é desse período que se pode acessar documentos registrados pela escrita, para poder aferir essa relação do humano com o tempo (embora traga comigo a hipótese de que essa perturbação sentida seja muito anterior à própria invenção do registro material, ou da escrita fonética). Esse fenômeno perturba os nossos sonhos desde que o humano tomou consciência de que o tempo está relacionado à finitude da vida, ou seja, à presença da morte.

Esse temor à morte, essa angústia da finitude do tempo, e, consequentemente, da existência, levou o ser humano a representar o tempo de maneiras diferentes, fato que acaba por expressar, por meio dos registros materiais, como a sua relação com esse fenômeno também mudou.

Para cumprir essa árdua tarefa, em tão pouco tempo (observe como a questão do tempo aparece constantemente em nossa mente), será necessário fazer um recorte. Com 
isso, a proposta é iniciar a investigação da representação do tempo a partir das reflexões de Agostinho sobre o tempo e a sua extensão.

Depois, de maneira anacrônica, voltamos para o passado grego, ao seu passado mítico. Anterior, mesmo, ao período clássico e seus racionalismos filosóficos principalmente os de ordem aristotélica - os quais já se aproximavam de um cientificismo. Retorna-se ao momento da mitologia greco-romana, para resgatar uma das maneiras mais conhecidas de representação do tempo. A representação do tempo por meio da personificação dos deuses, ou seja, o tempo como Cronos, ou Saturno. O tempo como um deus devorador de seus próprios filhos.

Nesse momento observa-se a origem greco-romana das características do deus tempo, embora se estenda essa representação até a Idade Média e começo da Idade Moderna, principalmente nas influências clássicas sofridas pela arte nos períodos do Renascimento e do Neoclassicismo.

Ainda com foco no início da Idade Moderna, mais especificamente no Barroco, o interesse neste texto é observar a representação do tempo na tradição cristã, como uma expressão da finitude da vida, da finitude de todas as coisas, excetuando-se, é claro, o sagrado. Para isso, serão observados registros pictóricos característicos da época, denominados Memento Mori (memória da morte, lembrar da morte). Essas representações tinham a função de fazer com que o cristão não se esquecesse da finitude da vida e da importância da prudência, além do recato em sua existência, para que pudesse alcançar uma vida eterna no paraíso.

Finalmente, como último recorte deste artigo, pretende-se observar o tempo sem passado da Modernidade e o tempo sem futuro da Pós-Modernidade, para fechar o ciclo de investigações das representações do tempo, com uma amostragem que possa apresentar as mudanças da representação do tempo.

Em razão das questões apresentadas acima, não estou me propondo a conceituar o tempo, seja fisicamente, fenomenologicamente ou filosoficamente. Pretendo, sim, refletir sobre as representações do tempo e suas transformações em diferentes períodos.

Dessa forma, este artigo encerra o anseio de não se comportar de modo descritivo, buscando apresentar as diferentes formas de representar o tempo. Trata-se, sim, de uma reflexão sobre como a relação entre o humano e o tempo se transformou, e de que forma esse humano buscou expressar, e projetar significados a esse fenômeno.

Ampliando as pesquisas da relação entre Pós-Modernidade, Comunicação e sociedade, desenvolvidas a partir do grupo de pesquisa Linguagem, Identidade, 
Sociedade - Estudos sobre Mídias (LISEM), da Universidade Presbiteriana Mackenzie, inscrito no Conselho Nacional de Desenvolvimento Científico e Tecnológico (CNPq), essa reflexão surge em resposta a um objetivo mais amplo, de uma pesquisa que se relaciona a outras publicações, com o propósito de aumentar o entendimento dos discursos que compõem o imaginário da Pós-Modernidade.

Este artigo busca encontrar a influência e a percepção que compõem a organização dos saberes e as representações dos fenômenos temporais em diferentes períodos, que vão desde representações criadas na Idade Média, até as produzidas no momento contemporâneo da Pós-Modernidade. Ou seja, ao lado de outros artigos (uns publicados, outros sendo produzidos), busca-se localizar os epistemes - os discursos que compõem o pensamento de uma determinada sociedade - para criar um mapa, uma representação do pensamento constituído na Pós-Modernidade. A ideia é, assim, desenvolver uma Arqueologia do Saber, assim como descreve Foucault (1990) em seu livro As Palavras e as Coisas. Essa reflexão epistemológica também se ampara no método arqueológico de Agamben (2019), apresentado no livro Signatura Rerun, onde o filósofo busca observar a relação entre a assinatura dos fenômenos, os paradigmas e a própria arqueologia.

\section{Das representações do tempo}

Começando por Agostinho, embora o filósofo medieval não tenha definido o tempo, refletiu sobre ele. Estando ligado a um raciocínio cristão, em suas reflexões, ele observa que a extensão do tempo é infinita, assim como a extensão da alma. Sendo alma e tempo infinitos, a extensão do tempo é equivalente à extensão da alma. Assim, não é possível pensar em presente, passado ou futuro, mas somente no presente (AGOSTINHO, 2007; FIORIN, 1996).

Dessa forma, Agostinho (2007) representa o tempo como um eterno presente. No entanto, embora exista apenas o presente, esse presente pode ser dividido em três tipos: O presente do passado, o presente do presente, e o presente do futuro.

O presente do passado é caracterizado pela memória. O presente do presente é o olhar, ou seja, a percepção imediata, o instante. Trata-se de um tempo excessivamente volátil, pois acaba a cada segundo. Finalmente, o último tipo dessa classificação trata do presente do futuro, o qual se caracteriza pela espera, pela projeção de um futuro imaginado, uma expectativa, ou seja, um tempo constituído pela esperança (AGOSTINHO, 2007). 
A partir dessa primeira reflexão de Agostinho é que se observarão as representações do tempo em outros períodos. Para o filósofo medieval, pode-se intuir que o tempo é um eterno presente, mas que o fiel deve esperar o futuro, para que sua alma possa adentrar a eternidade, pela sua esperança na promessa de um paraíso também eterno. O tempo como promessa, como esperança, ou seja, como fé.

A segunda representação do tempo a ser observada se refere aos tempos mitológicos anteriores à Antiguidade clássica, as representações míticas de Cronos ou Saturno (PANOFSKY, 2014). Nesse período, o humano busca explicar os fenômenos da natureza por meio dos deuses. Cronos, para a tradição grega, ou Saturno, para a tradição latina, apresentam uma representação do tempo como um deus devorador.

Saturno, e ou Cronos, é representado, algumas vezes, como um homem velho, com longas asas de pássaro, portando uma foice. Nessa representação pela tradição clássica, além de ser visto como o devorador, Saturno é também apresentado como o ceifador (PANOFSKY, 2014). Essa alegoria de um duplo Saturno, ceifador e devorador, nos faz pensar que a representação do tempo era de um fenômeno que ceifa a vida, que devora a existência dos seres humanos. Ou seja, o tempo, ou o pai tempo, é aquele que traz a finitude da vida. Por isso a sua representação de um deus tão cruel, capaz de devorar os próprios filhos. O tempo é aquele que devora e ceifa. O tempo é aquele que rouba a vida. O tempo como fim.

Nessa tradição, do tempo que rouba a vida, existe um tipo de representação de Saturno, encontrada com certa frequência em tratados alquímicos dos séculos XV, XVI e XVII, de um deus manco, ou, principalmente, com uma perna de pau, como se fosse um pirata (ROOB, 1997). Essa tradição localiza o deus Saturno como o patrono dos ladrões. Mas por que o patrono dos ladrões? Intui-se, por essas imagens, que Saturno pode ser considerado o patrono dos ladrões, pois ele, sendo o pai tempo, rouba aquilo que é de mais valor para os seres humanos, a vida. Do deus devorador e ceifador, da Antiguidade clássica, Saturno passa, no final da Idade Média e início da Moderna, a ser considerado, além da alegoria do tempo, patrono dos ladrões. Em consequência dessa representação, o tempo passa a ser visto como ator e como objeto, como ladrão e como posse. Afinal, o tempo é representado como Saturno, aquele que rouba a vida. Mas também como objeto a ser roubado: o tempo. Nesse sentido, o tempo é, simultaneamente, ator da ação e objeto a ser possuído. $O$ tempo como duplo.

Na Idade Moderna, no ocidente, com a hegemonia da fé cristã, o tempo e, consequentemente, Saturno, passa a ganhar outras representações. Uma delas é 
decorrente do processo de cristianização das representações da antiguidade clássica pagã. De pai tempo, Saturno vai deixando de ser representado como aquele ancião alado carregando uma foice, para se tornar a caveira, com manto negro, que, também carrega uma foice (PANOFSKY, 2014).

Nesse momento, tempo e morte se fundem, e agora a caveira vai se tornando um símbolo do tempo, um tempo de cautela, um tempo de prudência. Afinal, a caveira, para esse período, torna-se o aviso constante da finitude da vida, e, também, símbolo de sabedoria. Símbolo de sabedoria porque o "homem", ou seja, o humano sábio, é aquele que, embora tenha consciência da finitude da vida material, espera pela vida eterna da alma. Dessa forma, é possível concluir que o sábio é aquele que, tendo consciência, se desapega da vida material, preparando-se para a eternidade da alma. Esse pensamento combina com as ideias de infinitude da alma de Santo Agostinho.

Por isso, o tempo como espera, esperança e promessa mantém seu status nesse período. No entanto, para além do tempo como promessa, se tem o conhecimento advindo da consciência da morte. Então, a representação do tempo ganha a dimensão da sabedoria.

\section{O tempo como sabedoria.}

Esse tipo de representação pode ser vista no quadro de Holbein, Os Embaixadores (1533), onde uma caveira em anamorfose (perspectiva alterada), que mais parece uma mancha abstrata (quando não olhada no ângulo certo), faz a mediação entre os embaixadores, representando que ambos precisam de sabedoria para cumprir adequadamente as suas tarefas.

Além desse quadro como exemplo, é possível ver, de maneira constante, um tipo de pintura denominada Memento Mori. Traduzindo, ficaria: lembrar da morte, memória da morte. Ou seja, esse tipo de pintura desenvolvida, principalmente, na Idade Moderna, e comum nas representações do Barroco (comum nas representações da arte cristã dos franciscanos), busca retratar uma espécie de natureza morta, mas com a introdução de uma caveira. Nesse sentido, tanto tempo como morte se tornam representação de sabedoria, de prudência. A sabedoria que precisa ser relembrada, constantemente. $\mathbf{O}$

\section{tempo como lembrança, o tempo como prudência.}

Passando da Idade Moderna para a Modernidade, ou melhor, indo do século dezoito para o dezenove, cabe uma pergunta retórica para começar a reflexão sobre a representação do tempo: Que horas são?

Mas qual a importância dessa pergunta que parece tão corriqueira, diria óbvia? Sua importância está exatamente no fato de ser corriqueira e óbvia. Não por ser 
desprezível, mas pela capacidade de tornar-se invisível que o óbvio apresenta. Afinal, tudo que é óbvio parece tão natural, que não merece reflexão.

A naturalização do óbvio é uma questão observada por Barthes (1999), em seu livro Mitologias. Nesse livro Barthes observa a naturalização da ideologia, que, para o autor, acaba se tornando um mito, uma fala óbvia. "Para Roland Barthes de Mitologias (1957), o mito (ou ideologia) é o que transforma a história em natureza emprestando a signos arbitrários um conjunto de conotações aparentemente óbvio, inalterável" (EAGLETON, 1997, p.176).

Ou seja, a ideologia tratada de maneira óbvia deixa de ser um discurso histórico, e social, e passa a se tornar uma fala naturalizada, uma doxa, senso comum. Dessa forma, o mito deixa de ser histórico, passa a ser biológico, genético e hereditário. Essa passagem torna o mito um discurso óbvio, imutável, exatamente por deixar de ser histórico. Por causa disso é que o óbvio é invisível.

A partir dessa reflexão é que a pergunta "que horas são" torna-se relevante para compreendermos a representação das horas na contemporaneidade. Isso se dá, pois quando perguntamos que horas são, ela ganha um novo sentido na atualidade. Afinal, quando perguntamos que horas são, não pretendemos saber as horas, mas se busca saber quanto tempo falta. Sendo assim, a pergunta "que horas são" deve ser traduzida para: Quanto tempo falta?

Essa mudança de sentido da pergunta "que horas são" demonstra a nova relação que a sociedade pós-revolução industrial tem com o tempo, ou seja, o novo imaginário, a nova representação do tempo na atualidade, criando-se, assim, uma crise do tempo.

\footnotetext{
No entanto, como nova experiência no horizonte da Modernidade, surge, como descreveu detalhadamente Reinahrt Koselleck em vários de seus trabalhos, a sensação, e até mesmo a convicção explícita, de que seria o próprio tempo que estaria fora dos eixos; de que o persistente tempo de crise é o resultado de uma crise do tempo (ROSA, 2019, p. 28, grifo do autor).
}

O tempo para o sujeito moderno e pós-moderno (HALL, 2004) deixa de ser uma demarcação social e convencional das horas do dia para se tornar um momento de competição (ROSA, 2019), de auto-cobrança da necessidade de produção, ou seja, a imagem do tempo na contemporaneidade está relacionada ao momento industrial de produção. 
Hoje observa-se, ao contrário, o completo abandono e a reversão dessa relação: o projeto de vida serve ao objetivo de acompanhar o jogo de aumento, de permanecer ou tornar-se competitivo. Individual e coletivamente, fantasias de dar forma à vida, e as energias investidas, se direcionam, cada vez com mais intensidade, à manutenção da capacidade de aumento. A promessa fundante da Modernidade é quebrada com isso. Pela imposição da lógica de aumento exaure-se a margem de ação da autonomia, individual e política (ROSA, 2019, p. 25).

Produzir e ser produtivo, esse é o lema do sujeito contemporâneo. O tempo tornase um inimigo, pois disputamos constantemente com ele. Afinal, ele não só nos rouba a vida, mas agora diminui o nosso potencial de produção. O tempo não nos permite produzir o suficiente, e dificulta que sejamos capazes de cumprir todas as tarefas que a sociedade e que nós mesmos nos impomos. O tempo contemporâneo nos deixa ansioso: o tempo como ansiedade.

Embora o tempo como ansiedade seja comum tanto ao sujeito da Modernidade quanto ao da Pós-Modernidade, a perspectiva de ambos é diferente, pois o primeiro entende o tempo pela ausência de passado, enquanto o segundo, pela ausência de futuro. $\mathrm{Na}$ Modernidade temos um tempo sem passado, enquanto que na Pós-Modernidade temos um tempo sem futuro. Fenômeno que se aproxima do conceito de Rosa (2019, p. 37) de "desintegração das perspectivas de tempo cotidiano, tempo bibliográfico e tempo histórico", e a consequente visão renovada do tempo, como um passado sem referências e um futuro sem orientação e, com isso, sem possibilidade de se constituir como projeto.

Isso levaria à perda da capacidade de integração da própria vida de forma narrativa em um passado provedor de referências e um futuro provedor de sentido, e da capacidade de se obter, assim, uma orientação duradora, ao menos de médio prazo, para ações futuras (ROSA, 2019, p. 37).

Na Modernidade valoriza-se o tempo futuro, pois se apoia na promessa iluminista de um futuro tecnológico que libertará o humano das trevas. Ou seja, a promessa iluminista afirma que por meio da evolução científica, a razão libertará a sociedade das trevas da mistificação, forjando um humano mais esclarecido. Por isso a busca iluminista, e depois positivista da ordem e do progresso (lema gravado em nossa bandeira), projetava no imaginário humano uma representação de um futuro utópico. Um futuro onde a utopia do progresso criaria uma sociedade mais justa e libertaria o ser humano pelo esclarecimento. Com a metáfora da luz como razão, os iluministas acreditavam na iluminação, no esclarecimento e na libertação do ser humano pelo progresso. 
No entanto, se acompanharmos o raciocínio da Escola de Frankfurt, inspirada no marxismo e apresentada por Adorno e Horkheimer (2000) no artigo Indústria Cultural, o Iluminismo como Mistificação das Massas, o efeito foi contrário. A técnica, ao invés de libertar, acorrenta o ser humano, num processo de alienação pelo trabalho, produzida, principalmente, pelos dispositivos técnicos e de comunicação, por meio de uma fabricação artificial de informação e de cultura. Dessa maneira, o humano da Modernidade, que pela promessa iluminista seria libertado pela razão e pela tecnologia, acaba se alienando. Nesse processo, suas horas não são dedicadas ao esclarecimento, ao invés disso, acabam sendo preenchidas ou pelo trabalho, ou pelo entretenimento. Assim, o sujeito da Modernidade ou está dedicado à produção, à repetição rotineira do trabalho, ou está dedicado ao entretenimento, os quais entorpecem seus sentidos.

Por tais fatores é que o tempo da Modernidade torna-se um tempo sem passado, um tempo dedicado a um futuro, na verdade, a uma promessa de um futuro melhor, mais liberto e mais esclarecido. Devido a essa promessa, dedica a maior do seu tempo à produção, para um dia conquistar o direito de ter tempo, não para a reflexão, mas para a diversão e para o descanso. Novamente um tempo como promessa, mas não uma promessa de eternidade, uma promessa de um futuro material melhor. Um futuro para o entretenimento, para o prazer, para o descanso: o tempo como satisfação.

Sendo assim, o sujeito da Modernidade vive em função da promessa iluminista, de uma utopia vindoura que o trabalho, a produção e a técnica poderão proporcionar, desde que ele se dedique a essas três entidades. Essa imagem é muito bem representada no início do filme Tempos Modernos (1936), de Charlie Chaplin, onde um operário se aliena na rotina repetitiva até seu esgotamento, tudo em nome da busca de um futuro utópico que se baseia no progresso, na produção e na tecnologia. Por isso, o tempo da Modernidade é representado por uma valorização do futuro, da promessa iluminista de um futuro utópico, ou seja, um tempo sem passado.

Diferente da Modernidade e seu tempo sem passado, a Pós-Modernidade se apresenta por um tempo sem futuro, pois parece haver, no momento contemporâneo, uma grande valorização do passado em detrimento do futuro, além de uma necessidade intensa de se sentir todos os prazeres no momento presente.

O sujeito pós-moderno, por viver uma era de incertezas, também se influencia pela instabilidade, pela volatilidade de seu tempo, constituindo-se como uma identidade móvel, como afirma Hall (2004). 
O próprio processo de identificação, através do qual nos projetamos em nossas identidades culturais, tornou-se mais provisório, variável e problemático. Esse processo produz o sujeito pós-moderno, conceptualizado como não tendo uma identidade fixa, essencial ou permanente. A identidade torna-se uma "celebração móvel": formada e transformada continuamente em relação `as formas pelas quais somos representados ou interpelados nos sistemas culturais que nos rodeiam (Hall, 1987). É definida historicamente, e não biologicamente. O sujeito assume identidades diferentes em diferentes momentos, identidades que não são unificadas ao redor de um "eu" coerente. Dentro de nós há identidades contraditórias, empurrando em diferentes direções, de tal modo que nossas identificações estão sendo continuamente deslocadas. [...] A identidade completamente unificada, completa, segura e coerente é uma fantasia. Ao invés disso, à medida em que os sistemas de significação e representação cultural se multiplicam, somos confrontados por uma multiplicidade desconcertante e cambiante de identidades possíveis, com cada uma das quais poderíamos nos identificar - ao menos temporariamente (HALL, 2004, p. 12-13).

Nesse sentido, a percepção da incerteza afeta a capacidade de projeção, ou seja, a possibilidade de projetar um futuro, pois ele parece se mostrar também instável, volátil. Esse fenômeno parece levar o sujeito da Pós-Modernidade a desenvolver uma atenção muito centrada no passado, concordando com o conceito de retrotopia, do livro homônimo de Bauman (2017). No conceito, o autor (2017) verifica a tendência da PósModernidade de voltar-se ao passado. Essa saudade do passado parece se traduzir numa nostalgia diferente, pois o sujeito da Pós-Modernidade parece sentir uma nostalgia de um período em que não viveu. Saudades de um tempo não vivido. Ou seja, o sujeito da PósModernidade deixa de projetar utopias futuras - característica típica da modernidade para sonhar com utopias passadas, ou seja, utopias baseadas em memórias, em interpretações do passado: retrotopias.

Percebe-se o sintoma dessa nostalgia de um passado não vivido, por exemplo, nas questões relacionadas à estética e na representação de significados. Nas formas de representação de significados, como na arte, na moda, na publicidade, entre outras; o sujeito da Pós-Modernidade acaba se utilizando constantemente de intertextualidades para expressar suas ideias.

Entende-se por intertextualidade, de acordo com Barthes (2004), no livro Rumor da Língua, como sendo o cruzamento de culturas, de diferentes estéticas e períodos artísticos, por meio de citações, paródias, etc.

[...] um texto é feito de múltiplas escrituras, elaboradas a partir de diversas culturas e ingressante em uma relação mútua de diálogo, paródia, contestação; mas há um lugar em que esta multiplicidade é percebida, e este lugar [...] é o leitor: o leitor é o espaço em que se inscrevem, sem que nenhuma se perca, todas as citações que constituem a escritura: a unidade do texto não reside em 
sua origem, mas em seu destino, e este destino não pode ser pessoal: o leitor é alguém sem história, sem biografia, sem psicologia; ele é, simplesmente, um qualquer que articula, em um único campo, todos os traços a partir dos quais se constitui a escritura (BARTHES, 2004, p. 64).

Essa estratégia da Pós-Modernidade, o da intertextualidade, pode ser percebida, por exemplo, na busca constante desse sujeito pela citação a referências antigas. O vintage, ou a tendência retrô na moda (resgates ou misturas de estilos de outras épocas), são sintomas da retrotopia. A retrotopia, ou seja, projeções de passados nostálgicos (projetados e não necessariamente verossímeis ou vividos) se mostra como uma característica constante do sujeito da Pós-Modernidade.

Mas por quê?

Pela falta de futuro, uma visão compartilhada pela afirmativa de Harvey (1996).

\begin{abstract}
A popularidade de uma obra como O choque do futuro, de Alvin Toffler, reside precisamente em sua presciente apreciação da velocidade com a qual o futuro veio a ser descontado no presente. Também disso vem uma queda das distinções culturais entre, digamos, "ciência" e ficção "regular" (em obras como as de Thomas Pynchon e Doris Lessing), bem como a fusão do cinema de distração com o cinema de universos futurísticos. Podemos vincular a dimensão esquizofrênica da pós-modernidade que Jameson destaca [...] com acelerações dos tempos de giro na produção, na troca e no consumo, que produzem, por assim dizer, a perda de um sentido do futuro, exceto e na medida em que o futuro possa ser descontado do presente. A volatilidade e a efemeridade também tornam difícil manter qualquer sentido firme de continuidade. A experiência passada é comprimida em algum presente avassalador (HARVEY, 1996, p. 262-263).
\end{abstract}

Essa é uma das hipóteses reveladas para explicar a nostalgia de passados não vividos que assola a Pós-Modernidade: uma falta de segurança na projeção de um futuro. Afinal, como disse Santo Agostinho (2007), o presente do futuro é a espera. Ou seja, o futuro é um projeto a se concretizar, a se esperar. O futuro está relacionado à esperança (AGOSTINHO, 2007; FIORIN, 1996). No entanto, quando não se encontra a esperança, o que é o futuro?

Sem a esperança não existe futuro. Sem a existência de futuro, o que resta ao ser humano fazer? Voltar-se para o passado de maneira saudosa, nostálgica, e viver intensamente o presente, buscando satisfazer seus desejos no agora, nesse instante. Afinal, não há porque esperar um futuro, pois tudo é incerto.

Pois, de acordo com autores da Pós-Modernidade, como Lipovetsky e Serroy (2015), Bauman (1998), Han (2015) e Lyotard (2000), esse período está marcado pela sensação de incerteza, causada pelas constantes transformações que as metanarrativas têm 
sofrido. Metanarrativas, segundo Lyotard (2000), são os discursos que compõem a sociedade, como o religioso, o ético, o moral, o midiático, o político, o científico, etc. Essas transformações rápidas nos discursos levam o sujeito a questionar os modelos sociais, criando uma sensação de insegurança quanto às convenções que regem os acordos de uma sociedade no imaginário humano.

Modelos e perspectivas temporais, tanto individuais quanto coletivos, são, de acordo com a situação e contexto, redefinidos ("temporalizados") continuamente no fluxo do tempo, o que leva a formas históricas inéditas de "identidade situacional" e "política situacional" (ROSA, 2019, p. 43).

Mesmo a noção de progresso, que impulsionava a imaginação da Modernidade como um fenômeno positivo, é reavaliada na Pós-Modernidade. Ou seja, quando se tem a sensação de que tudo muda o tempo todo, a única certeza é que tudo é incerto. Se tudo é incerto, não há como projetar um futuro, e a noção de progresso acaba por sofrer uma rejeição (HARVEY, 1996).

\footnotetext{
Essa ruptura da ordem temporal de coisas também origina um peculiar tratamento do passado. Rejeitando a idéia de progresso, o pós-modernismo abandona todo sentido de continuidade e memória histórica, enquanto desenvolve uma incrível capacidade de pilhar a história e absorver tudo o que nela classifica como aspecto do presente (HARVEY, 1996, p. 58).
}

Se não é possível projetar um futuro, o que sobra para o sujeito da PósModernidade, senão buscar prazer, e viver intensamente o presente? Esse fator explica o hedonismo do humano pós-moderno. "Com efeito, a volatilidade torna extremamente difícil qualquer planejamento de longo prazo" (HARVEY, 1996, p. 259).

Além de buscar o prazer constante no tempo presente, o sujeito da PósModernidade volta-se para o passado. Um passado não vivido, mas projetado. Um passado idealizado: uma retrotopia (BAUMAN, 2017). Ou seja, na Pós-Modernidade ocorre uma falência das utopias, levando o sujeito a sonhar com um passado pleno de certezas. A busca do passado, para o ser humano pós-moderno, é traduzida por uma procura por certezas, já que a Pós-Modernidade não pode oferecê-las. Enfim, as incertezas da Pós-Modernidade levam o sujeito à incapacidade de projetar um futuro, por isso ele vive o presente e sente saudades de um passado que sequer viveu. Com isso a PósModernidade torna-se um tempo sem futuro. 
Considerações finais

O tempo como promessa, o tempo como fim, o tempo como duplo, o tempo como sabedoria, o tempo como lembrança, o tempo como prudência, o tempo como ansiedade, o tempo como satisfação, o tempo sem passado, o tempo sem futuro. Existem muitas representações do tempo, já que para todo ser humano, essa questão é fundamental, pois é no tempo que o humano reflete sua existência, sua permanência, sua duração, enfim, sua eternidade. Por isso, a cada período histórico, o humano reinventa o tempo. Cria novas representações desse tempo. O humano cria representações do tempo para explicar esse fenômeno, em nome de uma busca pela eternidade, pois ainda não se conformou com a finitude de sua existência.

Contudo, na Pós-Modernidade, esse tempo sem futuro e essa nostalgia das certezas de um passado idealizado, mas não vivido, têm criado alguns problemas, pois resgatam discursos que pareciam já extintos. O sujeito pós-moderno, buscando as certezas idealizadas desse passado idealizado, alia-se a qualquer discurso que prometa alguma certeza. Dessa maneira, observamos, muitas vezes, estarrecidos, outras, conformados, o ressurgimento de discursos mais fundamentalistas, os quais retomam preconceitos e se projetam, não pela razão, esperança iluminista, mas pela emoção. Murdock (2018), analisando a refeudalização de Jurgen Habermas, em relação à eleição de Donald Trump, observa esse fenômeno da ascensão de discursos que fogem da explicação racional para se aproximar do emocional. Nesse discurso emocional, principalmente no campo político, percebe-se em suas ações uma tendência populista baseada na performance, procurando manipular o eleitorado, "para promover uma visão de mundo específica" (MURDOCK, 2018, p.21). Essa visão de mundo específica exclui as contradições, o que abre caminho para um processo alienante. Embora promova a alienação, ganha o "consentimento" (MURDOCK, 2018, p.13) do sujeito da Pós-modernidade, pois é carregada de promessas de certezas de um passado idealizado, mas não vivido.

O filósofo enxerga esse apelo populista cuidadosamente planejado como "especialmente manipulador", já que evita os argumentos com base em evidências e explora as "tendências inconscientes" [...]. Uma vez obtido esse consentimento, cria-se um espaço no qual os políticos podem perseguir os interesses que foram ocultados ou marginalizados em seus discursos públicos. [...].Como os estudos dos frankfurtianos deixam claro, porém, o populismo autoritário que analisaram não poderia ser entendido simplesmente como um conjunto de imagens e dispositivos narrativos postos à disposição para promover uma visão de mundo específica. Ele precisava ser visto como um estilo particular de político que enfatizava a performance em detrimento do argumento (MURDOCK, 2018, p. 13-21). 
Por medo, por insegurança, concordando com Bauman (1998), o sujeito pósmoderno prefere a vigilância. Prefere a sensação de segurança ao invés da liberdade; a promessa ao invés da realidade; a nostalgia de um passado, do que um futuro incerto; a retrotopia à utopia.

Na busca pelas certezas em detrimento das incertezas, a Pós-Modernidade, em sua relação com o tempo, trilha um caminho perigoso quando cria sua representação de um tempo sem futuro. Pois nesse caminho acaba se iludindo por discursos e promessas de um passado inventado, projetado e idealizado. Essa idealização desse passado, o qual, anteriormente, criou projetos autoritários como o Nazismo, parece estar produzindo o mesmo efeito na Pós-modernidade. Onde, de maneira global, começam a pipocar lideranças que tem como projeto, o retorno nostálgico de tempos narrados, de discursos nostálgicos de passados idealizados: retrotopias. Sendo assim, o sujeito pós-moderno precisa afastar os medos, e aprender, urgentemente, a compreender que a existência é histórica, em construção, por isso incerta. Criando uma nova representação de um tempo racional, baseada, não em utopias ou retrotopias, mas na reflexão: um tempo como consciência.

Referências

ADORNO, Theodor; HORKHEIMER, Max. Indústria cultural: O Iluminismo como mistificação das Massas. In: LIMA, Luiz Costa. Teoria da cultura de massa. São Paulo: Paz e Terra, 2000. p. 169-214.

AGAMBEN, Giorgio. Signatura rerum. São Paulo: Boitempo, 2019.

AGOSTINHO. Confissões, 2007. Disponível em:

https://sumateologica.files.wordpress.com/2009/07/santo_agostinho_-_confissoes.pdf. Acesso em: 25 jun. 2019.

BARTHES, Roland. Mitologias. Rio de Janeiro: Bertrand, 1999.

BARTHES, Roland. O rumor da língua. São Paulo: Martins Fontes, 2004.

BAUMAN, Zygmunt. O mal-estar da Pós-Modernidade. Rio de Janeiro: Zahar, 1998.

BAUMAN, Zygmunt. Retrotopia. Rio de Janeiro: Zahar, 2017.

EAGLETON, Terry. Ideologia. São Paulo: Boitempo, 1997.

FIORIN, José Luiz. As astúcias da enunciação. São Paulo: Ática, 1996. 
FOUCAULT, Michel. As palavras e as coisas. São Paulo: Martins Fontes, 1990.

HALL, Stuart. A identidade cultural na Pós-Modernidade. Rio de Janeiro: DP\&A, 2004.

HAN, Byung-Chul. Sociedade do cansaço. Petrópolis: Vozes, 2015.

HARVEY, David. Condição pós-moderna. São Paulo: Loyola, 1996.

LIPOVETSKY, Gilles; SERROY, Jean. A estetização do mundo: viver na era do capitalismo artista. São Paulo: Companhia das Letras, 2015.

LYOTARD, Jean-François. A condição pós-moderna. Rio de Janeiro: J. Olympio, 2000.

MURDOCK, Graham. Refeudalização revisitada: a destruição da democracia deliberativa. Matrizes, São Paulo, v. 12, n. 2, p. 13-31, maio/ago. 2018. Disponível em: http://www.revistas.usp.br/matrizes/article/view/149601/147033. Acesso em: 14 set. 2018.

PANOFSKY, Erwin. Significado nas Artes Visuais. São Paulo: Perspectiva, 2014.

ROOB, Alexander. Alquimia e misticismo. Lisboa: Taschen, 1997.

ROSA, Hartmut. Aceleração: a transformação das estruturas temporais na

Modernidade. São Paulo: Ed. Unesp, 2019.

Submetido em: 16.08 .2019

Aprovado em: 30.10 .2019 